HACK, J. E. (1957). J. gen. Microbiol. 17, 625-630

\title{
The Effect of Spore Germination and Development on Plate Counts of Fungi in Soil
}

\author{
By JUDITH E. HACK \\ Glasshouse Crops Research Institute, Littlehampton, Sussex
}

SUMMARY: Spores of Didymella lycopersici and of six soil fungi were introduced separately into small quantities of soil spread in a film over a microscope slide. Direct observations were made, following which the soil from the slides was used for plate counts at stages before and after spore germination, when mycelium had developed, and after fruiting. It was found that as soon as spores germinated numbers obtained by plating decreased in the case of four of the seven fungi tested and did not increase as mycelial development progressed but reflected immediately the occurrence of sporulation.

Spores of many fungi added to sterilized soil germinate, develop a mycelium and finally form fruiting bodies. The question arises, how are these changes reflected in plate counts made at different times on inoculated soil? Although plate counts are constantly in use for the quantitative assessment of fungi in soil, no comparison of the directly observed stages of development of the fungus with the numbers of colonies obtained on plating has been made, so far as the author is aware. In connexion with an investigation of Didymella lycopersici a method for studying the behaviour of the fungus in soil microscopically was developed such that previously examined material could be plated. Plate counts were found to be very misleading at some stages in the ontogeny of the fungus. The study was therefore extended to six other fungi isolated from soil.

\section{METHODS}

A medium loam from one of the Cheshunt Experimental Station glasshouses was used. Tomatoes had been grown continuously on it for many years and it had been partially sterilized by steam almost annually. Spores of Didymella lycopersici introduced into this soil when unsteamed for a year or more slowly died out but germinated and grew when it was partially or completely sterilized. For direct observations fungi were grown in a thin layer of soil on glass slides. These slides (hereafter referred to as soil slides) were prepared by coating an area previously roughened with pumice stone with a thin layer of purified $1 \%$ agar at $45^{\circ}$ and immediately sprinkling it with air-dry soil from a sprinkler consisting of a boiling-tube closed by muslin. After drying, excess soil was tapped off, leaving approximately $0.1 \mathrm{~g}$. distributed over an area $\frac{3}{4} \mathrm{in} . \times 2 \mathrm{in}$. (slides were $\frac{3}{4}$ in. $\times 3$ in.). The thin layer of soil provided ample pore space where fungus spores and mycelium could be seen under the low or high dry objective.

The slides were placed in boiling tubes containing moist filter paper and kept in a horizontal position. They were autoclaved when desired. Spore suspension $(0 \cdot 1 \mathrm{ml}$.) was used to inoculate each slide; this was sufficient to moisten the 
soil. After inoculation the slides were incubated in a water-saturated atmosphere at room temperature. After each slide had been examined microscopically for germination and development, it was used for plate counts. It was transferred to a boiling tube containing $10 \mathrm{ml}$. water and the film of soil was rubbed off by a sterile section-lifter. The tube was then shaken, diluted appropriately and plated.

Comparisons were made between counts from soil slides and plate counts from soil in flasks $(25 \mathrm{~g}$. in $100 \mathrm{ml}$. flasks at $30 \%$ moisture content calculated on an oven-dry basis). For the first two experiments Sleeth (1945) agar was employed, modified by the addition of $\mathbf{0 . 0 0 6 7} \%$ Rose Bengal and diminution of the glucose content to $0.5 \%(\mathrm{w} / \mathrm{v})$. For the third experiment Waksman's peptone glucose agar for fungi (1928) was used. Counts of Didymella lycopersici did not differ on the two media.

Cultures of the fungi for the third experiment had been isolated from the soil used and maintained for about a year on Czapek-Dox agar. The strain of Didymella lycopersici came from diseased tomato stems, having been isolated five years previously and since then grown on Czapek-Dox agar.

\section{RESULTS}

Comparisons in unsteamed and sterilized soil. Nine flasks of soil and 9 soil slides were autoclaved for $2 \mathrm{hr}$. at $126^{\circ}$; an equal number of slides was not sterilized. Slides were inoculated with 50,000 spores of Didymella lycopersici in $0.1 \mathrm{ml}$. of water, and flasks with $12.5 \times 10^{6}$ spores in $1 \mathrm{ml}$. of water. Three slides and three flasks of each series were plated immediately, three slides and flasks of each $24 \mathrm{hr}$. later, and the remainder after 4 days of incubation. Before plating, all except the initial slides were examined under the microscope. The results are shown in Table 1.

Table 1. Numbers of colonies from plate counts and appearance of Didymella lycopersici in sterilized and unsterilized soil

\begin{tabular}{|c|c|c|c|c|c|c|}
\hline \multirow{3}{*}{$\begin{array}{l}\text { Duration } \\
\text { of incu- } \\
\text { bation } \\
\text { (days) }\end{array}$} & \multicolumn{3}{|c|}{ Sterilized soil } & \multicolumn{3}{|c|}{ Unsterilized soil } \\
\hline & \multicolumn{2}{|c|}{$\begin{array}{c}\text { Percentage } \\
\text { original number } \\
\text { (av. } 3 \text { replicates) }\end{array}$} & \multirow{2}{*}{$\begin{array}{l}\text { Appearance of } \\
\text { fungus (slides) }\end{array}$} & \multicolumn{2}{|c|}{$\begin{array}{c}\text { Percentage } \\
\text { original number } \\
\text { (av. } 3 \text { replicates) }\end{array}$} & \multirow{2}{*}{$\begin{array}{l}\text { Appearance of } \\
\text { fungus (slides) }\end{array}$} \\
\hline & Flasks & Slides & & Flasks & Slides & \\
\hline 1 & 1.7 & $5 \cdot 5$ & $\begin{array}{l}93 \% \text { germination. } \\
\text { Germ tubes still } \\
\text { short }\end{array}$ & 105 & 97 & $\begin{array}{l}\text { No spores } \\
\text { germinated }\end{array}$ \\
\hline 4 & $8 \cdot 3$ & $14 \cdot 0$ & $\begin{array}{l}\text { Mycelium exten- } \\
\text { sively developed } \\
\text { over entire soil area }\end{array}$ & 109 & 84 & $\begin{array}{l}\text { No spores } \\
\text { germinated }\end{array}$ \\
\hline
\end{tabular}

Figures in black are significantly different from previous day ( $T$ tests).

Plate counts from sterilized soil made one day after inoculation, whether of flasks or slides, showed a large decrease in the number of Didymella lycopersici, but direct observation showed that most of the spores had germinated and begun vigorous development. On the other hand, where spores did not 
germinate, in unsterilized soil, there was no significant change in the quantitive estimate of $D$. lycopersici present.

Comparisons in sterilized and partially sterilized soil. Eighteen flasks of soil and 18 soil slides were autoclaved for $2 \mathrm{hr}$. at $126^{\circ} ; 18$ flasks and 18 slides were autoclaved for $5 \mathrm{~min}$. at $115^{\circ}$. The flasks were inoculated as for the first experiment, and three slides and three flasks of each treatment were plated immediately and then after 1, 2, 4, 15 and 29 days of incubation. Before plating all except the initial slides were examined under the microscope (Table 2).

Table 2. Numbers of colonies and appearance of Didymella lycopersici in sterilized and partially sterilized soil

\begin{tabular}{|c|c|c|c|c|c|c|}
\hline \multirow{3}{*}{$\begin{array}{c}\text { Dura- } \\
\text { tion of } \\
\text { incuba- } \\
\text { tion } \\
\text { (days) }\end{array}$} & \multicolumn{3}{|c|}{ Sterilized soil } & \multicolumn{3}{|c|}{ Partially sterilized soil } \\
\hline & \multicolumn{2}{|c|}{$\begin{array}{c}\text { Percentage } \\
\text { original number } \\
\text { (av. } 3 \text { replicates) }\end{array}$} & \multirow{2}{*}{$\begin{array}{l}\text { Appearance of } \\
\text { fungus (slides) }\end{array}$} & \multicolumn{2}{|c|}{$\begin{array}{c}\text { Percentage } \\
\text { original number } \\
\text { (av. } 3 \text { replicates) }\end{array}$} & \multirow{2}{*}{$\begin{array}{l}\text { Appearance of } \\
\text { fungus (slides) }\end{array}$} \\
\hline & Flasks & Slides & & Flasks & Slides & \\
\hline 1 & $15 \cdot 6$ & $47 \cdot 2$ & $\begin{array}{l}95 \% \text { germination. } \\
\text { Germ tubes still } \\
\text { short }\end{array}$ & 32.9 & 43.8 & $\begin{array}{l}92 \% \text { germination. } \\
\text { Germ tubes still } \\
\text { short }\end{array}$ \\
\hline 2 & $11 \cdot 0$ & $55 \cdot 1$ & $\begin{array}{l}\text { Mycelium de- } \\
\text { veloping vigorously }\end{array}$ & $64 \cdot 4$ & $29 \cdot 2$ & $\begin{array}{l}\text { Mycelium de- } \\
\text { veloping vigo- } \\
\text { rously. A few } \\
\text { bacteria present }\end{array}$ \\
\hline 4 & $13 \cdot 7$ & $83 \cdot 1$ & $\begin{array}{l}\text { Mycelium covering } \\
\text { slide }\end{array}$ & $35 \cdot 6$ & $28 \cdot 1$ & $\begin{array}{l}\text { Mycelium cover- } \\
\text { ing slide }\end{array}$ \\
\hline 15 & 2051 & 11,800 & $\begin{array}{l}\text { Mycelium as at } \\
\mathbf{4} \text { days. A total } \\
\text { of } 37 \text { pycnidia } \\
\text { with spores seen }\end{array}$ & $24 \cdot 8$ & $\begin{array}{c}34 \cdot 8 \\
1292 *\end{array}$ & $\begin{array}{l}\text { Mycelium as at } \\
4 \text { days. Bacteria } \\
\text { profuse. No } \\
\text { pycnidia seen }\end{array}$ \\
\hline 29 & 6395 & 13,400 & $\begin{array}{l}\text { As at } 15 \text { days. } \\
27 \text { pycnidia seen }\end{array}$ & $\mathbf{5 2 . 0}$ & $\begin{array}{l}24 \cdot 7 \\
329 \dagger\end{array}$ & As at 15 days \\
\hline
\end{tabular}

Figures in black are significantly different from the previous day ( $T$ test).

* Two slides had low numbers on plating, one gave $1292 \%$.

$\dagger$ One slide gave $24.7 \%$ on plating, the mean of the others was $329 \%$.

As in the first experiment germination and growth of the spores caused a decrease in numbers, and despite profuse growth the original value for the population was not regained until sporing took place. Development on slides was more rapid than in flasks, and on the partially sterilized slides some sporing appeared to have occurred, although no pycnidia were observed. The examination for pycnidia consisted in following the high-power field across each slide five times at intervals covering the slide length. Such an examination might easily miss the presumably few (by comparison with the sterilized slides) pycnidia present. The slight sporing on the partially sterilized slides as opposed to flasks might be due to the heat treatment having a more drastic effect on $0 \cdot 1 \mathrm{~g}$. soil than on $25 \mathrm{~g}$. bulk soil.

Effect of germination and development of other fungi on plate counts. Soil slides were prepared and autoclaved for $2 \mathrm{hr}$. at $126^{\circ}$. Spores of various fungi were added at the rate of approximately 50,000/slide. Three of each set 


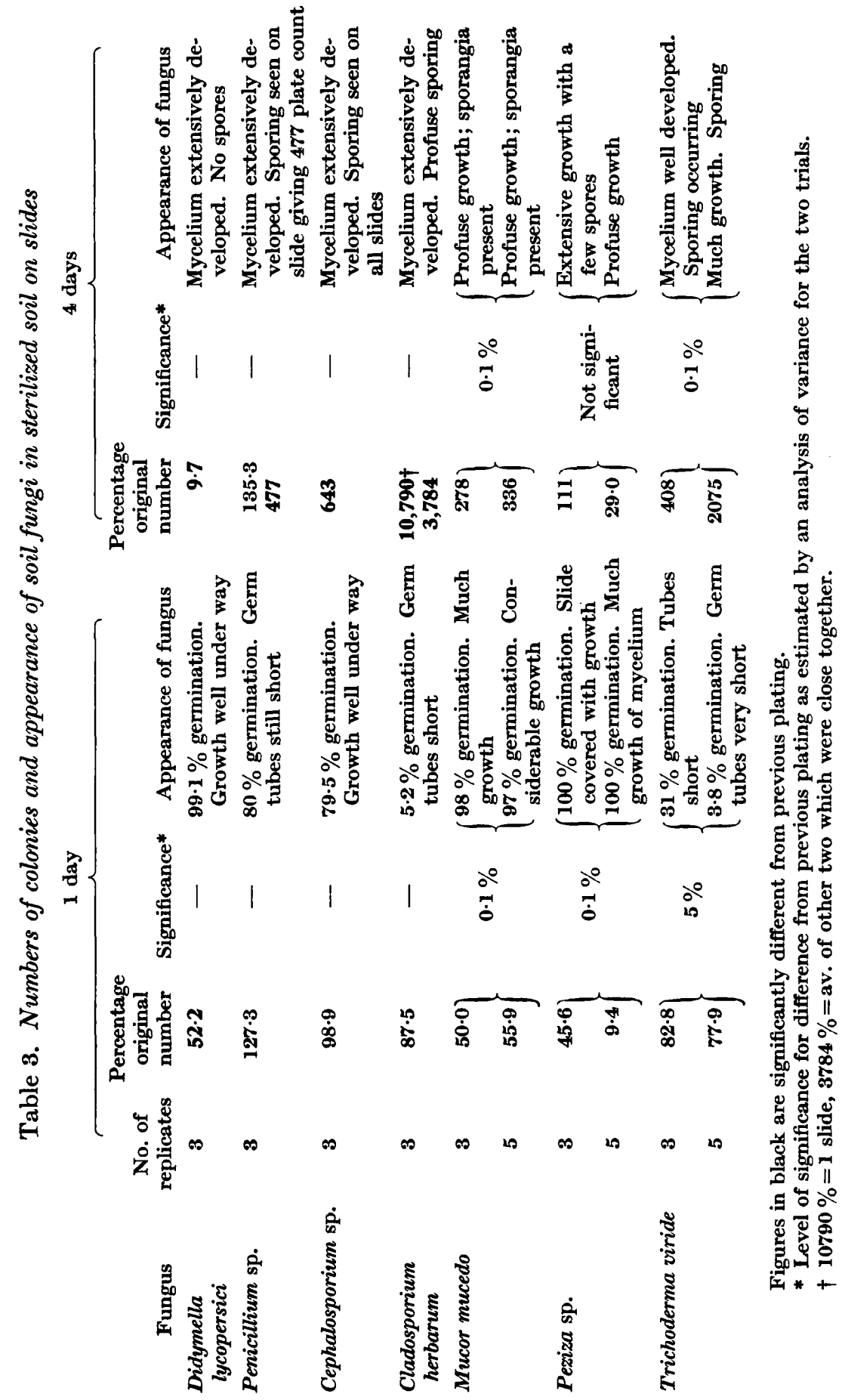


of slides were plated immediately and three of each set of slides after 1 and 4 days of incubation. Each slide was examined before plating, as before. The experiment was repeated with five replicates in the case of three of the fungi. The results are shown in Table 3. A further test was carried out in flasks of sterilized soil to see whether in bulk soil there was also an apparent decrease in the quantity of Mucor mucedo, Peziza sp. and Trichoderma viride after short incubation. There were five replicate flasks of each fungus for each plating, and the flasks were plated immediately after inoculation and after 1 and 4 days of incubation; the results are shown in Table 4.

Table 4. Numbers of colonies of three fungi in sterilized soil in flasks

\begin{tabular}{lcc}
\multicolumn{1}{c}{ Fungus } & $\begin{array}{c}\text { 1 day } \\
\text { (\% original number) }\end{array}$ & $\begin{array}{c}\text { 4 days } \\
\text { (\% original number) }\end{array}$ \\
Mucor mucedo & $\mathbf{6 . 8}$ & 2545 \\
Peziza sp. & $\mathbf{7 . 7}$ & 285 \\
Trichoderma viride & 69.4 & 3540
\end{tabular}

Figures in black are significantly different from previous plating.

The plate counts of flasks 1 and 4 days after inoculation give results very similar to the plate counts of slides. It appears probable that the decrease in numbers of the three fungi at 1 day and the great increase at 4 days are related as in soil slides to the germination of the spores inoculated and to the production of new spores.

It would be of interest to extend this type of study to a much larger number of soil fungi. Apart from Didymella lycopersici two of the six fungi investigated (Penicillium sp. and Cephalosporium sp.) appeared to possess mycelial properties which rendered them resistant to the plating process so that there was no decrease in the plate count when a high proportion of the spores had germinated. Two other organisms, Mucor mucedo and the Peziza sp., behaved similarly to Didymella lycopersici in that germinated spores and mycelium appeared to be relatively much more susceptible to the plating process than ungerminated spores. The behaviour of Cladosporium herbarum requires more work for its understanding. The decrease in the number of Trichoderma viride colonies after 1 day of incubation is less than that found for the other fungi and is not clearly related to spore germination. In the trial with five replicates (Table 3 ) there was a decrease of $22 \%$ at 1 day compared with the original number and only $3.8 \%$ spore germination. After 2 days, the numbers obtained on plating had not changed but germination was $70.4 \%$. It is possible that in the case of Trichoderma viride spores about to germinate are more susceptible to damage and elimination in the plating process than dormant spores.

\section{DISCUSSION}

The work reported here shows that colony counts of Didymella lycopersici are not a suitable measure of the development of the mycelium of this fungus in sterilized soil. With some fungi a given number of spores produce a far higher colony count on plates than the extensive mycelium which results from their germination and development. This may partly be due to failure to break up the 
mycelium during shaking, but certainly is partly the result of destruction of material in plating, for germinated spores not yet joined in a mycelial weft show this diminution.

Plate counts have long been held to underestimate the amount of mycelium in unsterilized soil. This supposition is supported by Warcup's direct examination of colonies in plates for their origin (1955). He did not find any which derived from hyphae, although in direct microscopic methods for estimating the quantity of fungi present in the soil the most common units are hyphal fragments (e.g. Skinner, Jones \& Mollison, 1952; McLennan \& Ducker, 1954). Presumably the count of germinated spores and mycelium would be decreased by plating in unsterilized soil, as in sterilized soil. Thus, if plate counts are mainly of spores and direct counts are mainly of hyphae, it is not surprising the two are not correlated when measured in connexion with changes in temperature, season, etc., for mycelium and spores would not be expected to vary together in nature.

In the early work of McLennan (1928) it appeared that the mycelial development of fungi in sterilized soil was not accompanied by great changes in plate counts but that sudden increases took place when sporing began. This has been confirmed by the work reported here, for in every case in which there were substantial increases in plate counts sporing was observed (with the exception of three slides of partially sterilized soil + Didymella lycopersici, discussed in connexion with the second experiment). The plate count may be regarded as a valuable method where interest is primarily in spores. For example, there are many papers reporting on changes in number of fungi introduced as spore suspensions into non-sterile soils (e.g. Katznelson, 1940; Rombouts, 1953; Park, 1955). It must be noted, however, that decreases such as are almost always recorded in these papers can only certainly be ascribed to death of the spores when it has been ascertained by some direct means that the fungus has not germinated.

\section{REFERENCES}

Fred, E. B. \& Waksman, S. A. (1928). Laboratory Manual of General Microbiology. New York: McGraw Hill.

Katznelson, H. (1940). Survival of micro-organisms introduced into soil. Soil Sci. 49, 283.

McLennan, E. (1928). The growth of fungi in soil. Ann. appl. Biol. 15, 95.

McLennan, E. I. \& Ducker, S. C. (1954). The ecology of the soil fungi of an Australian heathland. Austr. J. Bot. 2, 220.

Park, D. (1955). Experimental studies on the ecology of fungi in soil. Trans. Brit. Mycol. Soc. 38, 130.

Rombouts, J. E. (1953). The micro-organisms in the rhizosphere of banana plants in relation to susceptibility or resistance to Panama disease. Plant $\&$ Soil, 4, 276.

Skinner, F. A., Jones, P. C. T. \& Mollison, J. E. (1952). A comparison of a direct and plate counting technique for the quantitative estimation of soil microorganisms. J. gen. Microbiol. 6, 261.

SleEth, B. (1945). Agar medium and technique for isolating Pythium free of bacteria. Phytopathology, 35, 1030.

WARCUP, J. H. (1955). On the origin of colonies of fungi developing on soil dilution plates. Trans. Brit. mycol. Soc. 38, 298. 